\title{
BILE ACID CONTENT OF HUMAN SERUM. II. THE BINDING OF CHOLANIC ACIDS BY HUMAN PLASMA PROTEINS ${ }^{1}$
}

\author{
Bx DANIEL RUDMAN 2 AND FORREST E. KENDALL \\ (From the Columbia University Research Division, Goldwater Memorial Hospital and the \\ Department of Medicine, Columbia University, New York, N. Y.)
}

(Submitted for publication October 9, 1956; accepted December 6, 1956)

Although many observations indicate that bile acids and their derivatives may be bound by serum proteins, little information upon the quantitative aspects of this reaction is available. Lecomte du Noüy (1) observed that the activity of bile salts in lowering the surface tension of aqueous solutions was suppressed by the presence of serum.

The activity of human albumin in preventing the lysis of red blood cells by the bile salts was believed by $\mathrm{E}$. J. Cohn to indicate the binding of these substances by albumin (2). The bile acids which are contained in the serum of patients with hepatic disease have been found in this laboratory to be largely non-dialyzable (3). These observations indicate that these substances are bound by serum proteins. This binding to proteins is a factor which may influence the serum concentration and renal clearance of the bile acids, as well as their relationship to such other serum constituents as the lipids and bilirubin. The present report is concerned with the binding of several bile

TABLE I

Binding of bile acids by human plasma protein fractions

\begin{tabular}{ccccc}
\hline \hline \multirow{2}{*}{$\begin{array}{c}\text { Plasma } \\
\text { protein } \\
\text { fraction* } \\
\text { [Cohn (4)] }\end{array}$} & \begin{tabular}{c}
\multicolumn{4}{c}{$\mathrm{mM} \times \mathbf{1 0 - 3}$ of bile acid bound by } \\
$\mathbf{1 0 0} \mathrm{mg}$ of protein
\end{tabular} \\
\cline { 2 - 5 } & $\begin{array}{c}\text { Deoxy- } \\
\text { cholic } \\
\text { acid }\end{array}$ & $\begin{array}{c}\text { Cholic } \\
\text { acid }\end{array}$ & $\begin{array}{c}\text { Glycodeoxy- } \\
\text { cholic } \\
\text { acid }\end{array}$ & $\begin{array}{c}\text { Glyco- } \\
\text { cholic } \\
\text { acid }\end{array}$ \\
\hline I & 0 & 0 & & \\
II & 0 & 0 & 1.6 & 0 \\
III & 1.5 & 0 & 1.6 & 0 \\
IV-1 & 1.8 & 0 & 1.3 & 1.3 \\
V & 3.3 & 1.4 & 3.3 & \\
\hline
\end{tabular}

* Major components of these fractions are as follows: I, fibrinogen; II, $\gamma$-globulin; III, $\beta$-globulins; IV-1, $\alpha$ globulins; V, albumin.

1 This investigation was supported in part by a research grant, H-52, from the National Heart Institute, National Institutes of Health, Public Health Service, and by grants from the Albert and Mary Lasker Foundation and the Ames Company.

2 Fellow of the New York Heart Association. acids by certain plasma protein fractions, as measured by the dialysis-equilibrium method, and with the effect of $\mathrm{pH}$ upon this reaction.

\section{MATERIALS AND METHODS}

Studies were made of the amount of bile acid bound by the different fractions of human serum protein isolated by Cohn's method (4). Ten ml. of a 1 per cent solution of each fraction in buffer $(0.15 \mathrm{M} \mathrm{NaCl}, 0.01 \mathrm{M} \mathrm{Na}$ phosphate, $\mathrm{pH}$ 7.6) was placed in a small cellophane dialysis sac and equilibrated at $5^{\circ} \mathrm{C}$ for 48 hours against $50 \mathrm{ml}$. of a solution of the sodium salt of a cholanic acid dissolved in the same buffer. At the same time $10 \mathrm{ml}$. of buffer were equilibrated against $50 \mathrm{ml}$. of the solution of cholanic acid.s

After equilibration with buffer or serum protein, the bile acid concentration in the outer solution was determined spectrophotometrically $(5,6)$ on an aliquot of from 1 to $3 \mathrm{ml} .4$ The concentration of cholanic acid in the outer solution, which represents also the concentration of unbound bile acid within the sac, makes it possible to calculate the total quantity of unbound bile acid. By subtraction of unbound bile acid from the total bile

8 The dialysis tubing was boiled three times and rinsed repeatedly with distilled water prior to use.

The equilibration was virtually complete after 24 hours. Increasing the time beyond 48 hours produced no further change in the concentration of the cholanic acids in the outside phase. When only buffer was placed in the sac, the concentration of cholanic acid after equilibration was identical in the inner and outer solutions, and was equal to the value calculated from dilution. There was no evidence of adsorption by the membrane itself.

4 In the spectrophotometric determination of bile acid possessing one hydroxyl group, the 65 per cent sulfuric acid reagent must be replaced by a 9 to 1 mixture of concentrated $\mathrm{H}_{2} \mathrm{SO}_{4}$ and glacial acetic acid, as was first shown in the case of lithocholic acid by Minibeck (7). Monohydroxy bile acids possessing a double bond in the ring system, however, exhibit a suitable ultraviolet absorption spectrum in 65 per cent $\mathrm{H}_{2} \mathrm{SO}_{4}$ after heating at $60^{\circ}$ for 15 minutes.

The contents of the sac were not analyzed since the presence of the protein decreases the exactness of the cholanic acid determinations. 
acid content of the system, the quantity of bile acid bound by the protein within the sac was calculated.

The Donnan effect was considered to be of negligible magnitude and was disregarded in the calculations.

Commercial samples of deoxycholic acid, hyodeoxycholic acid and cholic acid were employed in these studies. The following compounds were kindly supplied by Dr. Erwin H. Mosbach: Taurine and glycine conjugates of deoxycholic and cholic acids; chenodeoxycholic acid; lithocholic acid; 7-hydroxy cholanic acid; 3-hydroxy 12keto cholanic acid; 3, 7-dihydroxy 12-keto cholanic acid; and the formyl derivatives of deoxycholic and cholic acids. 3, 12-dihydroxy 7-keto cholanic acid was donated by Dr. Norman A. Hulme of Sterling-Winthrop Research Institute. 3-hydroxy, 12-keto, $\Delta 9-11$ cholenic acid was given by Dr. Karl Pfister of Merck Research Laboratories. The protein fractions of human plasma were generously donated by Dr. J. M. Ashworth of the American Red Cross through E. R. Squibb and Sons.

\section{RESULTS}

Binding of bile acids by various plasma proteins

The extent of binding of deoxycholic and cholic acids, by $100 \mathrm{mg}$. of each of 5 plasma protein fractions, is indicated by Table $\mathrm{I}$. The protein, in a volume of $10 \mathrm{ml}$, was equilibrated against $12.7 \times$ $10^{-3} \mathrm{mM}$ of bile acid in a volume of $50 \mathrm{ml}$. Among the plasma proteins albumin exhibits the greatest binding activity towards both of these bile acids. The uptake of deoxycholic and glycodeoxycholic acids by Fractions III and IV-1 was approximately half that shown by albumin. Fibrinogen and gamma globulin did not bind either deoxycholic or cholic acid.

\section{Extent of binding by albumin of the series of cholanic acids}

The chemical structure of the bile acid was found to influence the extent to which it is bound to human serum albumin.

Ten ml. of a 1 per cent human serum albumin solution $\left(1.4 \times 10^{-3} \mathrm{mM}\right.$ of albumin $)$ was equilibrated with $50 \mathrm{ml}$. of buffer containing $12.7 \times$ $10^{-3} \mathrm{mM}$ of a number of bile acids and their derivatives. Table II lists the bile acids and derivatives studied, together with the number of moles of the bile acid bound by each mole of albumin under these conditions. The extent of binding decreases as the number of hydroxyl groups on the ring system is increased. It was greatest for the bile acids with a single hydroxyl group and least for cholic acid, which has three hydroxyl groups. The posi- tion of the hydroxyl groups in the ring system has little influence upon the degree of binding. Neither conjugation of the carboxyl group with glycine or taurine, nor covering up the hydroxyl groups by the formyl radicals greatly changed the extent of binding.

The introduction of a keto group in either the 7 or 12 position of the ring system suppresses the affinity for albumin. In the only unsaturated compound tested (3-hydroxy, 12-keto, $\Delta 9-11$ cho-

\section{TABLE II}

Binding of various cholanic acids by human serum albumin

Common name $\quad$ Structure $\quad \begin{gathered}\text { Moles of } \\ \text { cholanic } \\ \text { acid } \\ \text { bound by } \\ \text { one mole } \\ \text { of albumin }\end{gathered}$

Monohydroxycholanic acids

Lithocholic acid

3-OH cholanic acid

7-OH cholanic acid

6.5

Dihydroxycholanic acids

Deoxycholic acid

Hyodeoxycholic acid

Chenodeoxycholic acid

3,12 di-OH cholanic acid

3,6 di-OH cholanic acid

3,7 di-OH cholanic acid

Trihydroxycholanic acids

Cholic acid

$3,7,12$ trihydroxycholanic acid

Conjugated cholanic acids

Glycodeoxycholic acid

Taurodeoxycholic acid

Glycocholic acid

Taurocholic acid

Ketocholanic acids

-
-
-
- (Unsaturated)

3, 12 di-OH cholanyl

3, 12 di-OH cholanyl taurine

$3,7,12$ tri-OH cholanyl glycine

3, 7, 12 tri-OH cholanyl taurine

3-OH, 12-keto cholanic acid

3, 7 di-OH, 12-keto cholanic acid

3, 12 dihydroxy 7 -

keto cholanic acid $\quad 0^{*}$

3-OH, 12-keto, $\Delta$

9-11 cholenic acid

\section{Formylated cholanic acids}

Diformyldeoxycholic acid Diformyl 3, 12 dihydroxy cholanic acid

Triformylcholic acid

Triformyl 3, 7, 12 trihydroxy cholanic acid

* With larger amounts of albumin, it is possible to demonstrate slight binding of these two cholanic acid derivatives by albumin. 


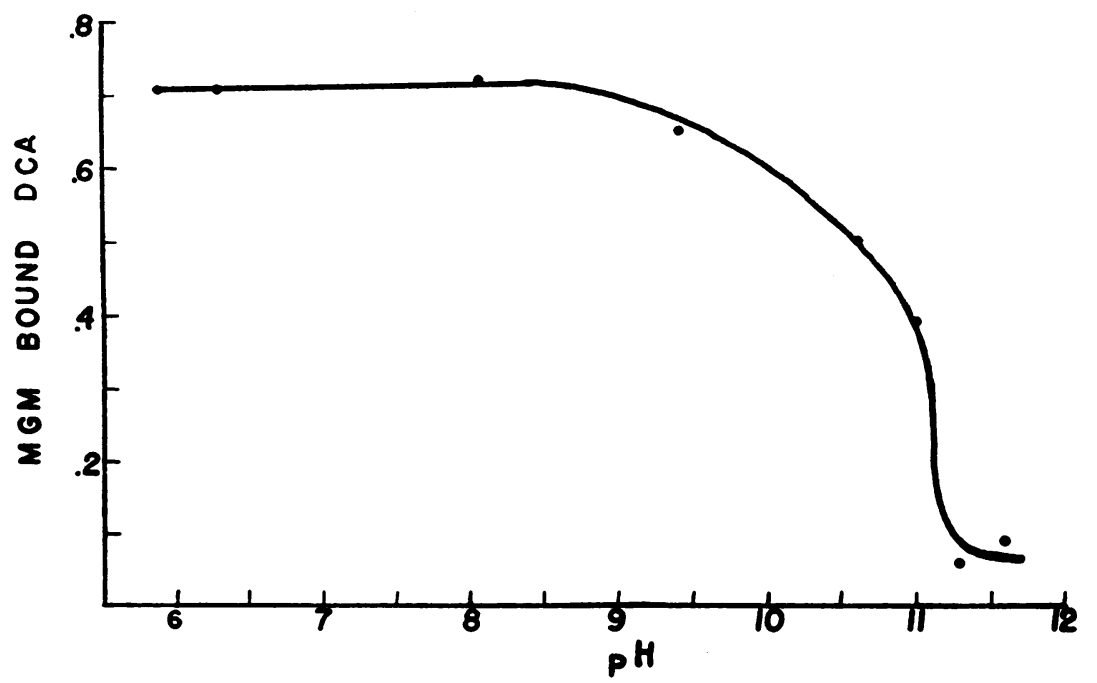

Fig. 1. The Binding of Deoxycholic Acid by 50 mg. of Human Albumin at VARIOUS PH'S

Five $\mathrm{ml}$. of 1 per cent albumin solution in buffer was dialyzed against $2.5 \mathrm{mg}$. of sodium deoxycholate in a volume of $25 \mathrm{ml}$. of buffer.

lenic acid), the introduction of a double bond into the ring system increased the extent of binding with albumin.

\section{Effect of $p H$ on binding reaction}

The effect of hydrogen ion concentration upon the interaction with albumin was studied, in the case of deoxycholic acid, over a $\mathrm{pH}$ range of 5.9 to 11.6 (Figure 1). The reaction is indifferent to hydrogen ion concentration until the $\mathrm{pH}$ of 9.0 is reached. Above $\mathrm{pH} 9.0$ the affinity for albumin decreases rapidly, and is nearly absent above $\mathrm{pH}$ 11.0. Denaturation of albumin by alkaline $\mathrm{pH}$ was excluded by the finding that the albumin solutions, after the experiment had been completed, exhibited the usual uptake of deoxycholate at $\mathrm{pH}$ 7.6.

\section{Calculation of binding constants}

It is apparent from Table II that each molecule of albumin can bind more than one molecule of cholanic acid. The number of molecules of cholanic acid bound by one molecule of albumin is determined by the concentration of unbound cholanic acid. The relationship between bound and unbound cholanic acid involves two parameters: the dissociation constant of the albumin-bile acid complex $(\mathrm{K})$ and the maximum binding capacity of the albumin molecule ( $\mathrm{n}$ ).

If it is assumed that in a molecule the size of albumin, the reactivity of a binding site is not markedly affected by the state of other binding sites, then the reaction can be treated as a simple bi-molecular reaction between the binding site and the cholanic acid.

The equilibrium conditions of this reaction may be formulated as follows ( 8$)$ :

$$
1 / \mathrm{r}=\mathrm{K} / \mathrm{n} 1 /(\mathrm{A})+1 / \mathrm{n}
$$

where $r$ is the ratio of moles of bound cholanic acid to moles of albumin; $\mathrm{A}$ is molar concentration of unbound cholanic acid; $n$ is maximum moles of cholanic acid which can be bound by one mole of albumin; and $\mathrm{K}$ is dissociation constant of the albumin-cholanic acid complex. It is apparent that a plot of $1 / r$ as a function of $1 / A$ should assume a linear form, the vertical intercept representing $1 / n$ and the slope representing $K / n$. By this method, the constants $K$ and $n$ may be calculated for each bile acid.

Such data have been obtained for deoxycholic acid and cholic acid (Figure 2). Solutions of the sodium salt of each bile acid in buffer, were prepared with a bile acid concentration of $1.27 \times 10^{-4}$, $2.54 \times 10^{-4}, 5.08 \times 10^{-4}$, and $12.70 \times 10^{-4} \mathrm{mM}$ 
per ml. Fifty $\mathrm{ml}$. of each solution were equilibrated with $10 \mathrm{ml}$. of a 1 per cent solution of albumin in buffer. Measurement of unbound bile acid concentration in the outer solution after equilibration, and calculation of quantity of bile acid bound by the albumin within the sac, provided the data for the curves in Figure 1. From the intercept and slope of these curves, it may be calculated that for deoxycholic acid, $\mathrm{K}=7.4 \times$ $10^{-4}$ and $\mathrm{n}=12$, for cholic acid, $\mathrm{K}=6.5 \times 10^{-4}$ and $n=4$.

\section{DISCUSSION}

The binding of the cholanic acid series of compounds by serum albumin might have been predicted from knowledge of the interaction of serum albumin with long chain fatty acids and with a variety of other organic anions (9). Serum albumin has been considered to be unique among the plasma protein fractions in its ability to bind organic anions (10). The present data confirm the preeminence of albumin in this regard, but indicate that the lipoprotein-containing Fractions III and IV-1 also interact with the cholanic acids, although to a lesser extent than does albumin.

The $\mathrm{pH}$ effect, namely the suppression of binding above $\mathrm{pH} \mathrm{9,} \mathrm{is} \mathrm{compatible} \mathrm{with} \mathrm{the} \mathrm{existence}$ of an electrostatic bond between the positively charged $\epsilon$-amino group of lysine (pK 9.3), and the negatively charged carboxylate group of the cholanic acid, as the primary force responsible for the binding. This finding parallels that of Klotz and Walker in the binding of methyl orange by bovine serum albumin (11).

However, the existence of secondary forces between albumin and the bile acid is indicated by the variation in extent of binding among closely related cholanic acids (Table II). The data indicate that the polarization of the cholanic acid ring system by the successive introduction of hydroxyl groups suppresses the affinity for albumin.

There are three times as many sites in albumin available for binding deoxycholic acid, a dihydroxy compound, as are available for binding cholic acid, which possesses 3 hydroxy groups. These observations are consistent with the postulated role of van der Waal forces acting upon the non-polar region of the smaller molecule, in determining the affinity of the substance for albumin

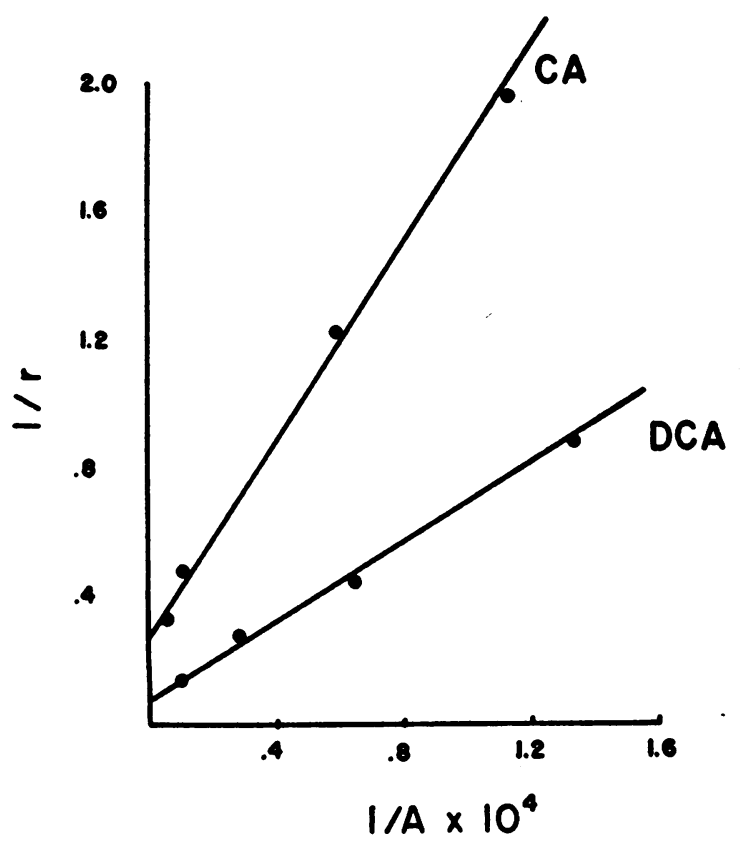

Fig. 2. Binding of Deoxycholic Acid (DCA) and Cholic Acid (CA) by Human Albumin as a Function of Concentration of the Unbound Actd

(10). The marked reduction of affinity for albumin which results from the presence of a keto group in the ring system, likewise appears to be caused by changes in the polarity of the ring system.

The cyclopentano-perhydrophenanthrene ring system of the bile acids is also found in such biologically important substances as cholesterol, steroid hormones, and cardiac glycosides, which differ from one another in the structure of the ring system and in the nature of substituent groups upon the ring. Study of how the interaction of cholanic acids with albumin is modified by changes in the structure of the cholanic acids may yield information of interest. The testing of additional cholanic acid derivatives will provide further information on the relationship between molecular structure and affinity for the various plasma proteins.

\section{SUMMARY}

The binding of bile acids and their derivatives by the protein fractions of human plasma has been studied by the dialysis-equilibrium method. Albumin exhibits the greatest binding activity to- 
wards these compounds. The lipoprotein-containing globulins, Cohn Fractions III and IV-1, bind approximately half as much deoxycholic acid and cholic acid as does albumin. $\gamma$-globulin and fibrinogen do not interact with the bile acids.

The affinity for albumin is reduced by the introduction of polar groups into the steroid nucleus. Thus the extent of binding decreases in the order monohydroxy $>$ dihydroxy $>$ trihydroxy cholanic acid. Binding of keto-cholanic acids to albumin could not be detected.

The effect of $\mathrm{pH}$ upon the binding: reaction suggests that the primary attraction between albumin and the cholanic acids is an electrostatic bond between the positively-charged lysine side chains of the former and the negatively-charged carboxyl groups of the latter.

The binding constants of albumin with two bile acids were calculated.

\section{REFERENCES}

1. Lecomte du Noüy, P., Sur la capacité d'adsorption des protéines du sérum vis-à-vis des sels biliaires. Compt. rend. Soc. de biol., 1928, 99, 1097.

2. Cohn, E. J., The chemical specificity of the interaction of diverse human plasma proteins. Blood, 1948, 3, 471.

3. Rudman, D., and Kendall, F. E., Bile acid content of human serum. I. Serum bile acids in patients with hepatic disease. J. Clin. Invest., 1957, 36, 530.

4. Cohn, E. J., Strong, L. E., Hughes, W. L., Jr., Mulford, D. J., Ashworth, J. N., Melin, M., and Taylor, H. L., Preparation and properties of serum and plasma proteins. IV. A system for the separation into fractions of the protein and lipoprotein components of biological tissues and fluids. J. Am. Chem. Soc., 1946, 68, 459.

5. Eriksson, S., and Sjövall, J., The absorption spectra of bile acids in sulfuric acid. Bile acids and steroids 31. Ark. Kemi, 1955, 8, 303.

6. Mosbach, E. H., Kalinsky, H. J., Halpern, E., and Kendall, F. E., Determination of deoxycholic and cholic acids in bile. Arch. Biochem. \& Biophys., 1954, 51, 402.

7. Minibeck, $H$., Beiträge zur quantitativen fluoreszphotometrischen Mikroanalyse. II. Mitteilung: Eine Methode zur Bestimmung der Gallensäuren im Serum und in serösen Flüssigkeiten mit dem "Fluoroquant." Biochem. Ztschr., 1938, $297,29$.

8. Teresi, J. D., and Luck, J. M., The combination of organic anions with serum albumin. VI. Quantitative studies by equilibrium dialysis. J. Biol. Chem., 1948, 174, 653.

9. Goldstein, A., The interactions of drugs and plasma proteins. J. Pharmacol. \& Exper. Therap., 1949, 95, 102.

10. Luck, J. M., The combination of fatty acid anions with proteins. Disc. Faraday Soc., 1949, 6, 44.

11. Klotz, I. M., and Walker, F. M., The binding of organic ions by proteins. Charge and $\mathrm{pH}$ effects. J. Am. Chem. Soc., 1947, 69, 1609.

\section{SPECIAL NOTICE TO SUBSCRIBERS}

After May 1, 1957 Dr. Philip K. Bondy will be Editor-inChief of The Journal of Clinical Investigation. The offices will move at this date to:

\section{Cedar Street}

New Haven 11, Conn. 